\title{
Interacción y reciprocidad: protagonistas y escenarios
}

\author{
Maura Pompa Mansilla
}

La forma en la que nos relacionamos con el mundo se vincula en buena medida con el conocimiento y entendimiento que tenemos de él. Hablar de interacción tiene que ver con las acciones que se ejercen de forma recíproca entre dos o más elementos, personas, funciones, objetos, etcétera; y al decir recíproca nos referimos a que a cada acción le corresponde una reacción, esto que ya establecía Newton en su tercera ley, relacionada con la mecánica clásica pero que ayuda a explicar lo que entendemos por interacción. Cuando interactuamos establecemos una relación, en donde lo que hacemos tiene un efecto sobre el elemento con el que estamos interactuando y al hacerlo éste tiene a su vez otro efecto en nosotros. En este sentido, en este número de la Revista Digital Universitaria (RDU) el lector podrá adentrarse y leer sobre diferentes interacciones que se dan entre diversos personajes, elementos y escenarios.

Un punto de partida para entender nuestro lugar en el mundo bien podría ser el origen de la humanidad. Tenemos un mejor conocimiento biológico sobre el proceso evolutivo a partir de nuestros ancestros más antiguos y su entorno, pero ¿qué pasó con la evolución de nuestro cerebro y qué relación tiene con el desarrollo de la cultura y el aprendizaje? Este artículo nos plantea esa interrogante. La evolución cultural como sociedad comparte mucho con la evolución biológica, se trata de un proceso evolutivo mutuamente fortalecido. Desde la conquista del fuego, la construcción de los primeros artefactos, como aquellos que hicieron más fácil la tarea de cazar y destazar el alimento, es posible identificar manifestaciones de cultura en la forma de interactuar entre nuestros ancestros y el medio que les rodeaba. Como lo señala el autor, las cualidades de nuestro cerebro no son exclusivas de ese órgano sino de la persona, pues funcionamos como un sistema integral. Sin la cultura no hubiéramos sido capaces de adaptarnos a nuestro entorno, subsistir y llegar a vivir en las condiciones en las que lo hacemos ahora, y en ello el aprendizaje ocupa un lugar fundamental. Este texto nos ayuda a entender, además, cómo el lenguaje, la cooperación, la lucha por la supervivencia, la transmisión de conocimiento y muchos otros factores jugaron papeles decisivos en la forma en la que hoy interactuamos con nuestro medio y con los otros. Un recorrido que sin duda resulta interesante y nos ayuda a comprender quiénes somos.

Dol: http://doi.org/10.22201/cuaieed.16076079e.2020.21.5.0 
En el mismo orden de ideas, nuestra cultura alimenticia y las múltiples interacciones que hemos construido con la comida han sido determinantes en nuestra evolución y desarrollo como especie. Dentro de ello, ¿qué tanto nos hemos detenido a preguntamos sobre lo que significa el acto de llevarnos algo a la boca para que luego se transforme en nuestro interior y las implicaciones socioeco-culturales que ello tiene? Algo que comienza con un acto aparentemente tan sencillo, con un fin alimenticio, representa un sin fin de interacciones de distinta índole. Por ejemplo, ¿sabías que a veces comes quitosano? En este texto, nos adentraremos en qué es y para qué sirve, además de que nos proponen una alternativa sustentable para algunos de los alimentos que son comunes en nuestra dieta.

Del mismo modo, hay un fenómeno sobre cómo cambia nuestra interacción con la comida y la forma de alimentarnos cuando cursamos los estudios universitarios. Algo está pasando que aunque podamos o no tener buenos hábitos de estudio, aquellos relacionados con la alimentación en esta etapa de la vida no se caracterizan por ser los más saludables. Lo anterior es parte de lo que nos comparten las autoras en el artículo "La etapa universitaria y su relación con el sobrepeso y la obesidad". El asunto está en que este cambio acarrea de alguna manera trastornos en la salud que pueden convertirse en severos al llegar a una edad más adulta. ¿Por qué será que, si estamos aprendiendo sobre otros aspectos y formándonos para ejercer una profesión en el futuro cercano, no logramos incorporar el conocimiento sobre nuestra interacción con nuestro cuerpo y el efecto que tiene nuestra alimentación sobre éste?

Ahora bien, como parte del proceso de conocernos y tratar de comprender qué pasa con nosotros y las interacciones que se dan en nuestro cuerpo, muchos escuchamos la palabra lágrima o lágrimas y la relacionamos con el llanto, sea de felicidad o de tristeza. No obstante, hay un mundo por explorar detrás de ese valioso líquido que somos capaces de producir y del que nuestros ojos se benefician tanto. Es algo tan natural en nosotros y para nuestro cuerpo, que muchas veces, si no nos encontramos con algún padecimiento o incomodidad, no nos detenemos a pensar sobre ello. Este artículo nos abre los ojos para comprender que las lágrimas son tan importantes que alguna alteración en ellas nos puede estar diciendo que algo pasa con nosotros y que, en algunos casos, nuestra visión puede verse afectada y, por ende, la forma en la que percibimos e interactuamos el mundo también.

El interesarnos por lo que pasa en nuestro entorno, de qué forma estamos en él y qué interacciones hay entre aquellos elementos que alcanzamos a distinguir, ayuda a dimensionar nuestro propio efecto en la cadena de sucesos que tienen lugar en la serie de interacciones de las que formamos parte, nos demos cuenta o no. Así, es posible que llamen nuestra atención los procesos de una molécula excitada y su relación con la naturaleza. Estetexto nos abre la puerta a un fenómeno del que podemos ser testigos en un laboratorio o en un lugar más común para algunos de nosotros: la naturaleza. Sería fascinante reflexionar 
sobre lo que pasa con los distintos tipos de moléculas al interactuar con la luz a través de diferentes procesos, y así, la próxima vez que nos encontremos en un escenario donde eso esté sucediendo, mirarlo con otros ojos y saber e imaginar qué está ocurriendo detrás del telón.

Siendo la RDu una revista mexicana, algunos artículos de este número también nos invitan a hacer una pausa y preguntarnos: ¿qué tanto conocemos nuestra casa, México? Antes de mirar afuera, sobre todo con esta idea de que el pasto es más verde del otro lado de la cerca, hay que mirar y explorar lo propio.

De los 17 países del mundo clasificados como megadiversos, México ocupa el quinto lugar. Su biodiversidad es un orgullo que compartimos sus habitantes, dentro de ella, ocupamos el tercer lugar en el mundo en cuanto a mamíferos. ¿Cómo proteger algo que a veces no conocemos o alcanzamos a dimensionar? En ese sentido, el artículo "Chihuahua y la Colección Nacional de Mamíferos (cNmA) de la UNAM_. nos amplía el panorama y entendimiento de otros mamíferos, que como nosotros habitan este planeta, con los que compartimos nuestro espacio territorial, y con los que interactuamos directa o indirectamente. Este texto nos habla sobre el acervo de mamíferos silvestres más completo de América Latina: la cNma. Un aspecto importante es que el lector podrá no sólo conocer sobre la colección, sino que ésta se encuentra disponible para la comunidad académica con el fin de realizar estudios y tener un acercamiento más certero sobre la variedad de estos organismos que habitan en los ecosistemas del estado.

México, al ser un país megadiverso, cuenta con diferentes tipos de bosques, uno de ellos situado en Chamela, Jalisco. Éste es un santuario natural protegido donde el tipo de vegetación es bosque tropical caducifolio. Hoy en día sabemos que los bosques cumplen una función muy relevante, pero te has preguntado ¿qué les pasa después de experimentar fenómenos meteorológicos fuertes? Y si ¿Pueden los bosques tropicales resistir o recuperarse del impacto de los huracanes? Lugares como Chamela representan una sede para realizar investigaciones de este tipo y poder conocer con mayor detalle esos fenómenos y sus procesos, así como las interacciones entre sus elementos, entre ellos el ser humano; y así comprender, o intentarlo, cómo funcionan, para luego conservarlos y hacer que la interacción entre los humanos y la naturaleza sea tal que ambos se beneficien y sostengan mutuamente.

En este recorrido por México, que nos permiten los distintos artículos de este número, regresamos al norte del país, ahora para situarnos en Coahuila. Los museos son espacios donde apreciamos diferentes elementos que están dispuestos ahí con una intención para nosotros; pero ¿qué pasa cuando intentamos ver los elementos, objetos, o manifestaciones ahí exhibidos, desde otra perspectiva? ¿Qué sucede cuando encontramos una manera diferente de interactuar con ellos y una oportunidad para transmitir de otra forma aquello que es necesario que aprendamos para, en su momento, poder transmitir a otros? Tal es el caso del artículo "Museos y formación docente: un vínculo constante”, en 
donde los espacios museográficos de paleontología y arqueología se convierten en espacios formativos para los futuros docentes de educación básica.

En relación con los procesos formativos y la profesión docente, un aspecto fundamental es la manera en la que interactúa un profesor con su propia práctica, con su forma de ejercer y vivir la docencia, con los y las estudiantes y lo que representan en su docencia. En el artículo al cual hacemos referencia, las autoras nos dejan ver que la reflexividad y el mirarse a uno mismo críticamente en los procesos que implica la profesión docente son cruciales. Esto cobra un significado mayor si lo vemos como parte de la formación docente en la práctica, en donde los ajustes nunca se terminan. Se trata de procesos particulares para cada individuo, aunque otro puede guiarse del camino recorrido. No obstante, aunque se ponga el mismo traje no le quedará igual, tendrá que hacer los ajustes fara formar un traje a su medida.

Ahora bien, dentro de la temática educativa, hay diversas cuestiones que también es necesario reflexionar, en especial debido a la situación de la pandemia actual y la forma en la que los países del mundo han tenido que irse adaptando a nuevas formas de interactuar y de repensar las dinámicas establecidas. En este sentido, por un lado, este número de la RDu cuenta con dos artículos sobre recomendaciones, emitidas para afrontar el reto que representa la enseñanza remota de emergencia en los ámbitos socioafectivo y didáctico.

Por otro lado, existe una situación tangible y presente en el ámbito educativo desde hace tiempo, que "La interacción de los grupos sociales se ha intensificado y complejizado, por lo que los retos que surgen de esta realidad no son abordables desde una sola disciplina, por un solo profesionista o en una sola región" (Hofmann et al., 2020). Ante ello, resaltamos tres temas importantes en la educación, que evidencian que las universidades e Instituciones de Educación Superior (IES) del mundo han tenido que irse adecuando y ajustando, tarde o temprano, a los cambios sociales, culturales y globales. Primero, la deserción universitaria que, más allá de ser responsabilidad de los estudiantes, es en un evento multifactorial, en que las IEs también juegan un papel fundamental. Segundo, el uso de las Tecnologías de la Información y Comunicación (Tic) y cómo pueden innovar y mejorar las prácticas docentes y las experiencias en el estudiantado, incluso al aplicarse para la evaluación. Y tercero, la necesidad de que nuestra máxima casa de estudios, teniendo en cuenta las dinámicas y demandas de una sociedad como la que pertenecemos, se plantee si será posible internacionalizar las licenciaturas de la unam.

Finalmente, invitamos al lector a hacer un ejercicio con la imaginación y plantearse qué sería de un cuento o una historieta sin un dibujo, sin ilustraciones o imágenes que lo acompañen; cambiaría la forma en la que interactuamos son él. Lo mismo sucede con el tipo de imágenes, ilustraciones o dibujos que los acompañen, la forma en la que nos relacionamos y vivimos la experiencia podría cambiar totalmente dependiendo de cuáles sean. Y eso, en muchas ocasiones, 
depende del autor o autora detrás de ellos. Seguramente hemos oído del artista que funge como tres veces autor en la misma obra: autor de la historia, dibujante y colorista. Hablamos de Augusto Mora, quien ha sido reconocido con diferentes distinciones y apoyos por sus creaciones. En ellas, hay una persona por conocer y una obra qué reconocer. La entrevista a Augusto Mora nos cuenta la historia del autor detrás de esas creaciones y porqué resulta fascinante conocerlas.

Es por todo lo anterior que, desde la redacción de la RDU, te invitamos a adentrarte en este número con ojos curiosos, mente reflexiva y a echar mano de tus propias experiencias para mirar cada artículo desde donde tú estás. Sin duda, en ellos reconocerás partes de ti y enriquecerás la forma en la que ves y experimentas el mundo.

\section{Referencias}

* Hofmann, Pablo G., García-González, Tomás, Montiel Ayometzi, Cecilia y Sánchez Mendiola, Melchor. (2020, septiembre-octubre). ¿Internacionalizar las licenciaturas de la UnAm? Revista Digital Universitaria (RDU), 21(5). Dol: http://doi.org/10.22201/ cuaieed.16076079e.2020.21.5.13

\section{Cómo CITAR ESTE ARTículo}

* Pompa Mansilla, Maura. (2020, septiembre-octubre). Interacción y reciprocidad: protagonistas y escenarios. Revista Digital Universitaria (RDU), 21(5). Dol: http://doi. org/10.22201/cuaieed.16076079e.2020.21.5.0

Maura Pompa Mansilla

maurapompa@unam.mx

Licenciada en Pedagogía por la Facultad de Filosofía y Letras de la Universidad Nacional Autónoma de México (UnAm). Ha trabajado desde hace más de 14 años en instituciones del sector educativo, ocho de los cuales fue investigadora en el Centro de Estudios Educativos A.C. (CEE). Se ha desempeñado primordialmente como investigadora en educación en temas relacionados con equidad, educación indígena, evaluación y desempeño docente, inter y multi-culturalidad, identidad del profesorado, e inclusión de tic en el aula. Cuenta con algunas publicaciones al respecto en libros y revistas. También ha impartido diversos cursos y talleres a nivel local y nacional sobre las temáticas antes señaladas, y participado en congresos en México y el extranjero. Es docente de posgrado y actualmente se desemmpeña como Jefa del Departamento de Investigación Traslacional en Educación en la Coordinación de Universidad Abierta, Innovación Educativa y Educación a Distancia (CUAIEED). 